\title{
Factors associated with the development of renal complications of diabetes mellitus in São Paulo city
}

S.R.G. Ferreira ${ }^{1}$ and F.M. Pinto ${ }^{2}$

\author{
'Departamento de Medicina Preventiva and ${ }^{2}$ Disciplina de Nefrologia, \\ Departamento de Medicina, Universidade Federal de São Paulo, \\ 04023-062 São Paulo, SP, Brasil
}

\section{Correspondence \\ S.R.G. Ferreira \\ Departamento de Medicina \\ Preventiva \\ UNIFESP/EPM \\ Rua Botucatu, 740 \\ 04023-062 São Paulo, SP \\ Brasil \\ Fax: 55 (011) 549-5159 \\ E-mail: ferreira@medprev.epm.br}

Publication supported by FAPESP.

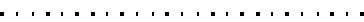

Received September 17, 1996 Accepted April 14, 1997

\begin{abstract}
The incidence of diabetic end-stage renal failure (ESRF) varies worldwide and risk factors have been demonstrated in several populations. The objective of the present study was to identify possible factors associated with the risk of development of ESRF in patients with diabetes mellitus (DM). Two groups of diabetic subjects were in-

Key words - Chronic renal failure

- Diabetes mellitus

- Diabetic nephropathy

- Associated factors
\end{abstract} cluded in a case-control study: 1) one group was submitted to renal replacement therapies, attending dialysis centers in São Paulo city and 2) the same number of controls without clinical nephropathy (two negative dipstick tests for urine protein), matched for duration of DM, were obtained from an outpatient clinic. A standardized questionnaire was used by a single investigator and additional data were obtained from the medical records of the patients. A total of 290 diabetic patients from 33 dialysis centers were identified, and 266 questionnaires were considered to contain reliable information. Male/female ratios were 1.13 for ESRF and 0.49 for the control group. A higher frequency of men was observed in the ESRF group when compared with controls (53 vs 33\%, $\mathrm{P}<0.00001)$, although logistic regression analysis did not confirm an association of gender and diabetic nephropathy (DN). Similar proportions of non-white individuals were found for both groups. Patients with insulin-dependent diabetes mellitus (IDDM) were less common than patients with non-insulindependent diabetes mellitus (NIDDM), particularly in the control group (3.4 vs 26.3\%, $\mathrm{P}<0.00001$, for controls and ESRF patients, respectively); this type of DM was associated with a higher risk of ESRF than NIDDM, as determined by univariate analysis or logistic regression $(\mathrm{OR}=4.1)$. Hypertension by the time of the DM diagnosis conferred a 1.4-fold higher risk of ESRF $(\mathrm{P}=0.04)$, but no difference was observed concerning the presence of a family history. Association between smoking and alcohol habits and increased risk was observed $(\mathrm{OR}=4.5$ and 5.9, respectively, $\mathrm{P}<0.001)$. A 2.4-fold higher risk of ESRF was demonstrated in patients with multiple hospitalizations due to DM decompensation, which suggested poor metabolic control. Photocoagulation and neuropathy were found to be strongly associated with ESRF but not with macrovascular disease. Data collected in our country reinforce the higher risk attributable to IDDM and the association between hypertension and the progression of DN. Indirect evidence for an association with metabolic control is also suggested. 


\section{Introduction}

The importance of diabetes mellitus (DM) in terms of public health has increased throughout the world. Changes in behavioral patterns, such as diet and physical activity, have contributed to a higher occurrence of obesity and inactivity in industrialized societies, and consequently to an increased risk of non-insulin-dependent diabetes mellitus (NIDDM). Advances in DM treatment have led to a decreased relative mortality rate and increased prevalence of chronic diabetic complications. Since the great majority of the diabetic population has NIDDM, macrovascular disease is considered to be the main cause of mortality among these individuals (1). In addition, microvascular disease at kidney level represents an important factor associated with mortality, particularly in insulin-dependent diabetes mellitus (IDDM) patients (2). Even if renal failure were not the direct cause of death in most NIDDM individuals, diabetic nephropathy (DN) has been suggested to be an independent risk factor of cardiovascular events (3-5).

According to the Multicenter Study on Prevalence of Diabetes (6), approximately $7.6 \%$ of the Brazilian adult population is diabetic. In a study conducted on the population under 15 years of age in three cities from the state of São Paulo, we found that almost 8 per 100,000 children become diabetic per year (7). Increasing IDDM incidence rates have been demonstrated in several countries $(8,9)$, affecting a young subset of the population at high risk to develop long-term complications of the disease. DN occurs in 35$40 \%$ of all IDDM patients during the course of their disease (10) compared with 6-20\% of NIDDM patients $(11,12)$. Among the latter, rates of about $50 \%$ have been reported in certain ethnic groups (13). As far as IDDM is concerned, the peak of cases of overt DN occurs 15 years after diagnosis and attempts to arrest the progression to end-stage renal failure (ESRF) have not been successful.
Data from the US, Europe, Japan and Scandinavia have shown an escalating trend in the proportion of diabetic patients with ESRF due to DM accepted for renal replacement therapy (14). Besides being a debilitating health problem, ESRF due to DM constitutes a relevant socioeconomic issue. In 1990, DN was the single most common cause of ESRF requiring therapy in the US, accounting for more than one-third of all cases, half of them IDDM and half NIDDM (15). The European Dialysis and Transplant Association has also reported high rates of ESRF due to DM (16) which was the most frequent cause, followed by glomerulonephritis and essential hypertension. Data from the LatinAmerican Society of Nephrology have shown that $19.7 \%$ of the patients who required dialysis in 1991 were diabetic (17). Variable percent contributions of DM to ESRF worldwide may suggest a variable risk to develop DN among populations. The clinical characteristics of the patients that progress to ESRF are found in the literature. The mean interval between diagnosis and institution of renal replacement therapy is about 20 years (12), or shorter (17-18 years) for European populations (16). As expected, IDDM patients develop ESRF earlier than NIDDM patients, and for both types dialysis is more common and earlier in men than in women (18). Pima Indians, Mexican Americans and Hispanics have been considered to be at high risk while the lowest incidence has been observed in Asian Americans (19). The reasons for such variability are not clear but are based, at least in part, on genetic predisposition. In addition to a genetic component, metabolic factors may contribute to the development of DN, particularly hyperglycemia (20). Long duration of the disease, mainly if combined with poor glycemic control, represents a major determinant of chronic diabetic complications. In IDDM, lipid profile disturbances (21), hypertension and/or a family history of hypertension $(22,23)$, smoking and high body mass index have also been associ- 
ated with DN $(24,25)$. Despite the considerable contribution of NIDDM to renal replacement therapy $(25,26)$, studies on risk factors in these patients are less common (27). In Brazil, a cross-sectional study evaluated characteristics of NIDDM patients who were proteinuric (28), but epidemiological data on risk factors for ESRF are not available. It is not known whether factors described for other populations are valid for the Brazilian population.

The V Brazilian Registry on Dialysis and Renal Transplant reported the following causes of ESRF: glomerulonephritis, nephrosclerosis, interstitial nephropathy, metabolic diseases (including DM), hereditary nephropathies, and others (29). Epidemiological data concerning dialysis procedures in the metropolitan area of São Paulo indicated that DM was the third most common cause of ESRF (30).

In view of the prevalence of DM in Brazil and its importance among the causes of ESRF, a study of the factors associated with its development is required. Due to the extensive racial admixture of the Brazilian population, comparisons with other populations are limited. Low socioeconomic level may be contributing to poor glycemic control and increased risk of chronic complications. The objective of the present study was to investigate some possible factors associated with the risk of development of diabetic renal complications in patients on dialysis programs in the city of São Paulo.

\section{Patients and Methods}

Two groups of diabetic subjects were included in a case-control study. The cases consisted of the whole population of patients submitted to renal replacement therapies attending dialysis centers in the city of São Paulo, each of them visited by one investigator. The control group consisted of diabetic patients matched for duration of DM without clinical evidence of DN. The exclusion of clinical DN was made on the basis of at least two negative dipstick tests for urine protein. Control subjects were obtained from an outpatient clinic at the Federal University of São Paulo, randomly selected as they were routinely visiting their physician, taking into account the matching criteria. A retrospective design was chosen since the process of renal impairment takes a long time to become established and also only a proportion of the diabetic patients will develop this complication. Patients with ESRF and the same number of control subjects were interviewed by the same investigator using a standardized questionnaire to assess prior exposure to specific factors. The data collected were based on this interview and were complemented with data from the medical records of the patients. Cases were excluded when lack of reliability regarding the information obtained was suspected. Questionnaires included birth date, gender, ethnic group, educational level, date of DM diagnosis, type of DM, number of insulin injections per day prior to dialysis therapy, number of hospitalizations due to DM, date of dialysis requirement, presence of hypertension prior to the DM diagnosis, family history of hypertension, concomitant diabetic complications and/or specific treatments, and smoking and alcohol habits. Since in some cases ethnic data were not available, cases and controls were classified into two ethnic groups: white and non-white (black, mulatto, Asian, etc.), according to the impression of the investigator. Classification of DM was checked by the investigator who classified as IDDM those patients whose age of onset was under 30 years, presenting classical signs and symptoms of insulinopenia or ketoacidosis, and requiring insulin therapy since the diagnosis; NIDDM patients were older than 40 years at the time of diagnosis, with a slowly developing disease, treated for at least one year with diet alone or associated with hypoglycemic agents, without ketoacidosis or a positive family history of DM. 
Educational level was used as an indirect index of socioeconomic level and three categories were set: I) illiteracy and incomplete primary schooling, II) complete primary schooling and incomplete secondary schooling, and III) complete secondary schooling and university education. The number of insulin injections and hospitalizations (I: up to one; II: 2 to 5 ; III: > 5 hospitalizations) was used as an indicator of metabolic control during the course of the disease. Chronic complications were considered to be positive when there was a history of retina photocoagulation, amaurosis or vitrectomy, in addition to previous myocardial infarction or angina, cerebrovascular disease, peripheral vascular disease, or signs/symptoms of peripheral and autonomic neuropathy. Subjects smoking seven or more cigarettes per day for the last eight years were considered to be smokers in this study; subjects who drank $\geq 1$ liter of a $10 \%$ alcoholic drink or $\geq 0.25$ liter of a $40 \%$ alcoholic drink or $\geq 2.0$ liters of beer, per day for more than five years, were considered to be alcoholics (31). Patients with a positive family history of hypertension were those with at least one first-degree relative undergoing antihypertensive treatment.

Parametric and non-parametric tests were used for statistical analysis. Comparison of DM duration between groups was made by the Mann-Whitney test. The unpaired Student $t$-test was used to compare patient age,

Table 1 - Characteristics of the two groups of diabetic subjects studied.

Data are reported as mean \pm SD or median and range. DM, Diabetes mellitus. ${ }^{*}$ Three cases suspected of chronic pancreatitis.

\begin{tabular}{lccc}
\hline & ESRF group & Control group & $\begin{array}{c}\text { ESRF vs control } \\
P\end{array}$ \\
\hline $\mathrm{N}$ (men/women) & $141 / 125$ & $88 / 178$ & 0.00001 \\
Age (years) & $55.1 \pm 13.4$ & $62.7 \pm 12.1$ & 0.0001 \\
Ethnic group (white/non-white) & $161 / 105$ & $155 / 111$ & $>0.05$ \\
DM duration (years) & $14.0(0.5-40)$ & $14.0(0.5-40)$ & $>0.05$ \\
DM type (IDDM/NIDDM) & $70 / 196$ & $9 / 257^{*}$ & 0.00001
\end{tabular}

reported as mean $\pm \mathrm{SD}$. Frequencies of variables in both groups were compared by the Fisher and chi-square tests in order to detect possible associations with ESRF, and odds ratios were obtained for each of the variables studied. Based on these results, logistic regression analysis was performed to evaluate the independent contribution of parameters. A two-sided $\mathrm{P}<0.05$ was considered to be significant.

\section{Results}

Thirty-three of the 34 eligible dialysis centers were visited and 290 diabetic patients were asked to answer the questionnaire. Twenty-four questionnaires were excluded due to lack of reliable information (physical or mental limitations of the patient). Of 266 patients undergoing dialysis, $\sim 60 \%$ were on hemodialysis and $\sim 40 \%$ on continuous ambulatory or intermittent peritoneal dialysis. A group of diabetic subjects without DN, matched to the ESRF patients for DM duration, was used as control. Median durations were the same for both groups of subjects (14.0 years, range $0.5-40$ years, $P$ $=0.9998$ ), whose characteristics are shown in Table 1. Considering duration of IDDM and NIDDM separately, IDDM patients in the ESRF group had a longer duration of the disease than those without DN (17.0 vs 13.0 years, $\mathrm{P}<0.05)$, which was not the case for NIDDM patients (14.0 and 14.5 years for ESRF and control subjects, respectively). By the time of the study, the mean age of the ESRF group was $55.1 \pm 13.4$ years $(52.0 \pm$ 13.0 years for women and $58.0 \pm 14.4$ for men), which was lower than in the control group $(62.7 \pm 12.1$ years, $\mathrm{P}<0.0001)$. At the onset of DM the mean age of patients who developed ESRF was $37.4 \pm 16.4$ years (17.4 \pm 10.4 years for IDDM and $44.4 \pm 11.4$ years for NIDDM); six patients started treatment with diet only (2.3\%), 190 also receijved oral hypoglycemic agents (71.4\%) and 70 (26.3\%) received insulin therapy. At DM 
diagnosis the control group was $48.9 \pm 10.8$ years old $(20.0 \pm 16.0$ years for IDDM and $49.0 \pm 11.0$ for NIDDM) and differed in terms of the distribution of the initial treatments $(5.6 \%$ on diet only, $89.9 \%$ with oral hypoglycemic agents and $14.5 \%$ with insulin, $\mathrm{P}<0.00001$ ), with a higher proportion being observed in the oral agent category. Male/female ratios were 1.13 for the ESRF patients and 0.49 for the controls. A higher frequency of men was observed in the ESRF group when compared with the control (53.0 vs $33.1 \%, \mathrm{P}<0.00001)$. A preponderance of white individuals was seen among the ESRF patients (60.5 vs 39.5\% non-whites) and the controls (58.3 vs $41.7 \%$ non-whites) and these proportions did not differ between groups. Three subjects of Asian origin were found in each group among those classified as non-whites, corresponding to approximately $1 \%$ of the whole group. The ESRF group consisted of 70 IDDM and 196 NIDDM patients; for the control group IDDM was even less common $(\mathrm{N}=9)$ and these proportions were found to be different between groups (3.4 vs $26.3 \%, \mathrm{P}<0.00001)$. The presence of chronic pancreatitis was suspected only in the ESRF group but could not be confirmed by radiological procedures.

Univariate analysis showed that patients with IDDM were associated with a 7.6-fold higher risk of ESRF than those with NIDDM. Excluding three patients suspected to have pancreatitis did not change this result. Educational level was significantly lower in the control group; ESRF patients had more hospitalizations due to DM decompensation than control subjects (Table 2). Also, photocoagulation was more frequently required in ESRF patients $(79.7$ vs $9.8 \%, \mathrm{P}<0.00001)$ and their risk to undergo this therapy was 36 times higher than for diabetic subjects without DN. A similar situation was observed for amaurosis (54 of 266 patients) and vitrectomy (15 of 266 patients), which did not occur in control subjects. On the other hand, frequencies of cataract surgery did not differ be- tween groups. Coronary heart disease $(6.8 v \mathrm{~s}$ $2.3 \%, \mathrm{P}<0.0001)$, cerebrovascular disease (4.5 vs $1.1 \%, \mathrm{P}<0.0001)$ and extremity amputations $(11.3$ vs $0.8 \%, \mathrm{P}<0.0001)$ were more common among the ESRF patients. The same pattern was observed with respect to peripheral (78.9vs $15.0 \%, \mathrm{P}<0.0001)$ and autonomic neuropathy (66.1 vs $17.1 \%, \mathrm{P}<$ 0.0001). Smoking and alcohol drinking habits were associated with the development of renal disease $(\mathrm{P}<0.0001)$. Patients with ESRF had been smoking eight cigarettes a day for a mean period of ten years and those without DN had been smoking two cigarettes a day for four years. Increases in the risks of 8.3 and 7.1, respectively, were attributed to the ESRF group. Hypertension diagnosed at the time of DM diagnosis or earlier occurred more frequently among ESRF patients, with their risk to develop this complication being 3.9-fold higher. A family history of hypertension also tended to be more common in this group (146 of 177 patients) when compared to the other (140 of 190 subjects, $\mathrm{P}=0.057)$.

Logistic regression analysis (Table 3 ) revealed the risk for a patient to develop ESRF when exposed to a certain factor, compared to the absence of such factor. In the presence

Table 2 - Distribution of subjects from the two groups studied according to educational level and number of hospitalizations due to DM.

Education: I = illiteracy and incomplete primary schooling; $\|$ = complete primary schooling and incomplete secondary schooling; III = complete secondary schooling and university education. Hospitalization: I = up to one; II = 2 to 5 ; III = >5. Higher educational level and number of hospitalizations were associated with ESRF $(P<0.0001)$.

\begin{tabular}{lrrr}
\hline & I & II & III \\
\hline ESRF group & & & \\
$\quad$ Education & 55 & 182 & 29 \\
$\quad$ Hospitalization & 184 & 54 & 28 \\
Control group & & & \\
$\quad$ Education & 122 & 130 & 14 \\
Hospitalization & 261 & 5 & 0
\end{tabular}


Table 3 - Results of logistic regression analysis.

$\mathrm{F}$ hypertension $=$ Family history of hypertension. Logit estimates; log likelihood $=-121.3568$; number of observations $=529 ;$ chi $^{2}=490.62 ;$ prob $>$ chi $^{2}=0.0000$; pseudo $R^{2}=0.6690$.

\begin{tabular}{lcccccc}
\hline & Odds ratio & Standard error & $z$ & P > |z| & $95 \%$ Confidence interval \\
\hline IDDM & 4.0842 & 3.0226 & 1.901 & 0.057 & 0.9575 & 17.4203 \\
Sex & 1.5332 & 0.5759 & 1.138 & 0.225 & 0.7343 & 3.2014 \\
Ethnic group & 0.8190 & 0.2847 & -0.574 & 0.566 & 0.3983 & 1.6188 \\
Age at diagnosis & 1.0080 & 0.0144 & 0.555 & 0.579 & 0.8181 & 1.0367 \\
Hospitalizations & 2.4379 & 0.6452 & 3.367 & 0.001 & 1.4513 & 4.0952 \\
Hypertension & 1.4068 & 0.2374 & 2.022 & 0.043 & 1.0106 & 1.9582 \\
F hypertension & 1.3764 & 0.5074 & 0.867 & 0.386 & 0.6683 & 2.8348 \\
Smoking & 4.5353 & 1.8524 & 3.702 & 0.000 & 2.0368 & 10.0987 \\
Alcohol & 5.9512 & 3.2468 & 3.269 & 0.001 & 2.0428 & 17.3377 \\
Photocoagulation & 13.7433 & 5.4215 & 6.643 & 0.000 & 6.3432 & 29.7766 \\
Peripheral neuropathy & 4.9344 & 2.1162 & 3.722 & 0.000 & 2.1290 & 11.4365 \\
Autonomic neuropathy & 5.9227 & 2.7259 & 3.865 & 0.000 & 2.4030 & 14.5979 \\
Coronary disease & 2.4385 & 2.1304 & 1.020 & 0.308 & 0.4090 & 13.5134 \\
Cerebrovascular disease & 3.7959 & 4.3148 & 1.173 & 0.241 & 0.9801 & 35.2283 \\
Peripheral vascular disease & 0.4668 & 0.2079 & -1.710 & 0.087 & 0.4400 & 1.1177
\end{tabular}

of IDDM, this risk proved to be 4.1 times higher than in the presence of NIDDM $(\mathrm{P}=$ 0.05). In contrast to the univariate analysis suggesting a male sex association with ESRF, no increase in this risk was detected by the logistic regression; the same was found regarding ethnic group, educational level and age at diagnosis. The association of ESRF risk with multiple hospitalizations was confirmed by this analysis which demonstrated a 2.4-fold increase when compared with a single hospitalization $(\mathrm{P}=0.001)$. Hypertension by the time of the diagnosis of DM conferred a 1.4 times higher risk for $\operatorname{ESRF}(\mathrm{P}$ $=0.04$ ) but no difference was observed concerning the presence of a family history. The association of smoking and alcoholism with an increased risk of renal complications was also confirmed (OR $=4.5$ and 5.9, respectively, $\mathrm{P}<0.001)$. Photocoagulation and neuropathy were found to be associated with ESRF but not with macrovascular disease.

\section{Discussion}

Considering the scarcity of data on the magnitude of DN as a cause of ESRF in Brazil, the present study provided an opportunity to evaluate this situation. Since hemodialysis is a specialized procedure, it requires sophisticated conditions such as those available in São Paulo state. This state still represents an important immigration center, resulting in high population admixture probably not comparable to any other worldwide.

The possibility of bias when choosing an outpatient clinic linked to the Federal University of São Paulo as the source of control patients should be considered. Patients with more complicated diabetic disease may be concentrated close to a teaching hospital. However, the detection of differences between the two groups, with and without DN, made our results even more significant. In addition, our findings are in agreement with 
those from the literature. When using DM duration as the matching parameter, the male/ female ratio differed between groups. It is known that women see doctors more frequently than men; the high proportion of female sex seen in the control group, which depended on spontaneous demand, may be due, at least in part, to this trend. The increased risk of ESRF attributable to the male sex (18) was initially suggested by univariate analysis which was not supported by logistic regression. We cannot exclude the influence of inadequate matching for this parameter, contributing to the lack of statistical significance. Actually, an odds ratio of 1.53 (53\% excess of men) suggested that significance could be achieved by increasing the sample. Logistic regression analysis revealed the importance of each type of DM for the risk of developing renal disease. IDDM conferred a 4.1 times higher risk of this complication when compared to NIDDM. Although these data showed borderline significance $(\mathrm{P}=$ 0.057), it is possible to confirm the existence of an association between IDDM and increased risk of DN, which is also supported by other studies (32). As far as ethnicity is concerned, a preponderance of white individuals is found in the São Paulo population (33) and the same pattern was demonstrable in the two groups studied. A similar percent contribution of Asian descendants submitted to dialysis was found as compared with the proportion seen in the general population of this state. No difference in risk of ESRF could be attributable to this parameter. Divergent results have been reported, with higher concentration of ESRF being found in blacks when compared to whites, adjusted to the general American population (34). In an attempt to clarify this finding, these investigators indicated the increased prevalence of NIDDM in the black population and speculated that other risk factors such as hypertension and poor metabolic control, which should be more frequent among them, may also play a role (35). Despite their high risk, black Americans undergoing dialysis showed lower mortality rates than whites, but this difference was not seen after kidney transplantation (36). This apparent disagreement between Brazilian and American data could be expected, if we consider the great admixture that characterizes our black population, which is not comparable to the black American population. Patients with ESRF were younger at the time of DM diagnosis and by the time of the study than controls. Most IDDM patients develop the disease during or after puberty, and for those who progress to ESRF the diagnosis of DM was established earlier. There is no consensus in the literature concerning the role of age at onset of DM on the risk of developing DN. Increased prevalence of microvascular complications and mortality rates have been described in patients who developed DM until puberty when compared with postpubertal DM (37), but other studies were discordant (38). Our data did not support a possible association between age at diagnosis and DN. One of the major factors involved in the risk of chronic complications of DM is glycemic control. The results of the Diabetes Control and Complications Trial (39) definitely confirmed the impact of strict metabolic control on preventing chronic diabetic complications. The design of this study did not permit conclusions about the relationship between metabolic control and the development of DN. However, if we consider that the number of hospitalizations due to DM decompensation may reflect long-term glycemic status to some extent, comparison of the two groups was compatible with an association of this parameter with the risk of ESRF, suggesting an adverse effect of hyperglycemia. In agreement, we also found an association between $\mathrm{DN}$ and other chronic complications, mainly retinopathy and neuropathy, consistently reported in the literature (20). Hyperglycemia constitutes the most common factor among all these complications. Association with retinopathy, as evalu- 
ated by the history of photocoagulation and vitrectomy, was expected since it represents the same microvascular disease located in territories other than the kidney. Also, patients with $\mathrm{DN}$ frequently have neurological disturbances and, in fact, some investigators have suggested a causal role for autonomic neuropathy in the genesis of renal injury (40). Macrovascular disease is seen as the main cause of mortality in diabetic subjects, in particular NIDDM patients (1), in contrast to the incidence of DN which is much lower than in IDDM (32). In both groups studied, the great majority of the patients evaluated had NIDDM, which could limit the demonstration of an association of ESRF with macrovascular disease by regression analysis. The importance of hyperglycemia in diabetic macroangiopathy has been poorly demonstrated, probably due to other concomitant risk factors commonly associated with DM such as hypertension, obesity and dyslipidemia. Hypertension was associated with DN as found in other studies (41-43) but as previously mentioned a family history was not, particularly in IDDM (22). In this type of DM, hypertension is interpreted as a manifestation of renal injury $(41,42)$, and its presence is strongly related to the progression to $\operatorname{ESRF}(44,45)$. In an attempt to demonstrate a possible role of hypertension as determinant of renal disease also in NIDDM, we only evaluated the association of hypertension detected prior to the definition of the diabetic condition. Using these criteria, we showed that hypertension almost doubled the risk of developing ESRF, corroborating the hypothesis of early systemic and renal hemodynamic abnormalities in the genesis of DN (46). Smoking has been associated with microalbuminuria in IDDM $(47,48)$, but it is not clear if it represents an independent factor contributing to the progression of renal disease (49). The thromboxane-induced vasoconstriction effect of smoking on temporary elevation of blood pressure (50) associated with the observation of insulin resistance among smokers (51) raises the possibility that smoking predisposes to a persistent blood pressure increase and consequently to renal damage. Our findings are consistent with a deleterious effect of smoking on the development of ESRF by diabetic patients. Association with alcohol drinking was not previously described, except for DM secondary to pancreatitis. Educational level, used as an indirect index of socioeconomic level, did not favor the hypothesis that low income predisposes to ESRF.

In summary, data collected in Brazil confirmed the higher risk of DN attributable to IDDM and the association of hypertension with the progression of diabetic renal disease. Indirect evidence for an association with metabolic control is also suggested.

\section{References}

1. Richard PD \& Trevor JO (1992). Diabetes mellitus and macrovascular complications - An epidemiological perspective. Diabetes Care, 15: 1141-1155.

2. Borch-Johnsen $K$, Krag-Andersen $P$ \& Deckert T (1985). The effect of proteinuria on relative mortality in type I (insulindependent) diabetes mellitus. Diabetologia, 28: 590-596.

3. Mogensen CE (1984). Microalbuminuria predicts clinical proteinuria and early mortality in maturity-onset diabetes. New England Journal of Medicine, 310: 356360.
4. Mattock MB, Morrish NH, Viberti GC, Keen H, Fitzgerald A \& Jackson G (1992). Prospective study of microalbuminuria as a predictor of mortality in NIDDM. Diabetes, 41: 736-741.

5. Alzaid AA (1996). Microalbuminuria in patients with NIDDM: An overview. Diabetes Care, 19: 79-84.

6. Malerbi DA \& Franco LJ (1992). Multicenter study of the prevalence of diabetes mellitus and impaired glucose tolerance in the urban Brazilian population aged 3069 yr. Diabetes Care, 15: 1509-1516.
7. Ferreira SRG, Franco LJ, Vivolo MA, Negrato CA, Simões ACP \& Ventureli CR (1993). Population-based incidence of IDDM in the State of São Paulo - Brazil. Diabetes Care, 16: 701-704.

8. Bingley PJ \& Gale EAM (1989). Raising incidence of IDDM in Europe. Diabetes Care, 12: 289-295.

9. Diabetes Epidemiology Research International Group (1990). Secular trends in incidence of childhood IDDM in 10 countries. Diabetes, 39: 858-864. 
10. Andersen AR, Sandahl CJ \& Andersen JK (1983). Diabetic nephropathy in type 1 (insulin-dependent) diabetes: an epidemiological study. Diabetologia, 25: 496501.

11. Fabre J, Balant LP, Fox HM \& Vernet AT (1982). The kidney in maturity onset diabetes mellitus: a clinical study of 50 patients. Kidney International, 21: 730-738.

12. Humphrey LL, Ballard DJ \& Frohneid PP (1989). Chronic renal failure in non-insulin dependent diabetes mellitus: a population-based study in Rochester, Minnesota. Annals of Internal Medicine, 111: 788-796.

13. Nelson RG, Newman JN, Knowler WC, Suvers ML, Kunzelman CL \& Pettit DJ (1988). Incidence of end-stage renal disease in type 2 (non-insulin dependent) diabetes mellitus in Pima Indians. Diabetologia, 31: 730-736.

14. Markell MS \& Friedman EA (1992). Diabetic nephropathy: management of endstage patients. Diabetes Care, 15: 12261236.

15. USRDS Annual Data Report (1991). Incidence and causes of treated ESRD. American Journal of Kidney Diseases, 18 (Suppl 2): 21-29.

16. Report on Management of Renal Failure in Europe, XXIII (1991). Nephrology Dialysis Transplantation, 7: 5-48.

17. Registro Latino Americano de Dialise y Transplante Renal - Informe de Diálise Ano 1991 - Sociedad Latinoamericana de Nefrologia - maio de 1993.

18. Pugh JA, Medina R \& Ramirez M (1993). Comparison of the course to end-stage renal disease of type 1 (insulin-dependent) and type 2 (non-insulin-dependent) diabetic nephropathy. Diabetologia, 36: 1094-1098.

19. Stephens GW, Gillaspy JA, Clyne D, Mejia A \& Pollak VE (1990). Racial differences in the incidence of end-stage renal disease in type I and II diabetes mellitus. American Journal of Kidney Diseases, 15: 562567.

20. Pirat J (1978). Diabetes mellitus and its degenerative complications: a prospective study of 4,400 patients observed between 1947 and 1973. Diabetes Care, 1: 168-188.

21. Coonroad BA, Ellis D, Becker D \& Bunker $C$ (1993). Predictor of microalbuminuria in individuals with IDDM. Pittsburg Complications Study. Diabetes Care, 16: 13761383.
22. Krolewski AS, Canessa M, Warran JH, Laffel LMB, Christlieb R, Knowler WC \& Rand LI (1988). Predisposition to hypertension and susceptibility to renal disease in insulin-dependent diabetes mellitus. New England Journal of Medicine, 318: 140-145.

23. Krolewski AS (1989). The natural history of diabetic nephropathy in type 1 diabetes and the role of hypertension. Annals of Internal Medicine, 110: 795-798.

24. Sawicki PT, Didjurgut V, Muhlauser I \& Bender R (1994). Smoking is associated with progression of diabetic nephropathy. Diabetes Care, 17: 126-131.

25. Retting B \& Teutsch SM (1984). The incidence of end-stage renal disease in type I and type II diabetes mellitus. Diabetic Nephropathy, 3: 26-27.

26. Grenfell A, Bewick M, Parsons V, Snowden S, Taubre D \& Watkins PJ (1988). Non-insulin dependent diabetes and renal replacement therapy. Diabetic Medicine, 5: 172-176.

27. West KM, Edreich LJ \& Stober JA (1980). A detailed study of risk factors for retinopathy and nephropathy in diabetes. Diabetes, 29: 501-508.

28. Gross JL, Stein ACR, Beck MO, Fuchs SC, Silverio SP, Azevedo MJ \& Friedman $R$ (1993). Risk factors for the development of proteinuria by type II (non-insulin dependent) diabetic patients. Brazilian Journal of Medical and Biological Research, 26: 1269-1278.

29. V Registro Brasileiro de Diálise e Transplante Renal (1993). In: XVII Congresso Brasileiro de Nefrologia da Sociedade Brasileira de Nefrologia, Fortaleza, 1994.

30. Sesso R, Anção MS, Madeira SA \& Comissão Regional de Nefrologia da Secretaria da Saúde de São Paulo e Centro de Informática da Escola Paulista de Medicina (1991). Aspectos epidemiológicos do tratamento dialítico na Grande São Paulo. Revista da Associação Médica Brasileira, 40: 10-14.

31. Marconi JT (1959). The concept of alcoholism. Quarterly Journal of Studies on Alcohol, 20: 216-235.

32. Pugh JA (1989). The epidemiology of diabetic nephropathy. Diabetes and Metabolism Reviews, 5: 531-546.
33. Fundação IBGE (1992). IX Recenseamento Geral do Brasil - 1980. Rio de Janeiro, Vol. 1, Tomo 4, 10-11.

34. Pao $\mathrm{Cl}$, Whittle JC, Whelton PK \& Sudler AJ (1992). The excess incidence of diabetic end-stage renal disease among blacks: a population-based study of potential explanatory factors. JAMA, 268: 3079-3084.

35. Cowie CC, Port FK, Wolfe RA, Savage PJ, Moll PP \& Hawthorme VM (1989). Disparities in incidence of diabetic end-stage renal disease according to race and type of diabetes. New England Journal of Medicine, 321: 1074-1079.

36. Cowie CC, Port FK, Rust KF \& Harris MI (1994). Differences in survival between black and white patients with diabetic end-stage renal disease. Diabetes Care, 17: 681-687.

37. Kostraba NJ, Dorman JS, Ochard TJ, Becker DJ, Ohki Y, Ellis D, Doft BH, Lobes LA, LaPorte RE \& Drash AL (1989). Contribution of diabetes duration before puberty to development of microvascular complications in IDDM subjects. Diabetes Care, 12: 686-693.

38. Krolewski AS, Warran JH, Christlieb AR, Busick EJ \& Kahn CR (1985). The changing natural history of nephropathy in type 1 diabetes. American Journal of Medicine, 78: 785-794.

39. Diabetes Control and Complications Trial (DCCT) Research Group (1995). Effect of intensive therapy on the development and progression of diabetic nephropathy in diabetes control and complications trial. Kidney International, 47: 1703-1720.

40. Spallone V, Gambardella S, Maiello MR, Barini A, Frontoni S \& Menzinger G (1994). Relationship between autonomic neuropathy, 24-h blood pressure profile and nephropathy in normotensive IDDM patients. Diabetes Care, 17: 578-584.

41. Christlieb AR, Warram JH, Krolewski AS, Busick EJ, Ganda OP \& Asmal AC (1981). Hypertension: the major risk factor in juvenile-onset insulin-dependent diabetics. Diabetes, 30 (Suppl 2): 90-96.

42. Mogensen $\mathrm{CE}$, Hansen KW, Osterby R \& Damsgaard E (1992). Blood pressure elevation versus abnormal albuminuria in the genesis and prediction of renal disease in diabetes. Diabetes Care, 15:11921204. 
43. Marshal SM \& Alberti KGMM (1989). Comparison of the prevalence and associate features of abnormal albumin excretion in insulin-dependent and non-insulindependent diabetes. Quarterly Journal of Medicine, 261: 61-71.

44. Parving HH \& Hommel E (1989). Prognosis in diabetic nephropathy. British Medical Journal, 299: 230-233.

45. Hasslacher C, Borgholte G, Ritz E \& Wahl $P$ (1989). Impact of hypertension on prognosis of IDDM. Diabetes and Metabolism, 15: 338-342.
46. Hostetter TH, Hennke HG \& Brenner BM (1981). Intrarenal hypertension in the initiation and progression of diabetic and other glomerulopathies. American Journal of Medicine, 72: 375-386.

47. Chase HP, Garg SK, Marshall G, Berg CL, Harris $S$, Jackson WE \& Hamman RE (1991). Cigarette smoking increases the risk of albuminuria among subjects with type 1 diabetes. JAMA, 265: 614-617.

48. Coper JJ, Staples AJ, Coccolone R, Nairn J, Badcock N \& Henning P (1994). Relationship of smoking and albuminuria in children with insulin-dependent diabetes. Diabetic Medicine, 11: 666-669.
49. Viberti GC, Yip-Messent J \& Morocutti A (1992). Diabetic nephropathy: Future avenue. Diabetes Care, 15: 1216-1225.

50. Claster JA \& Wood AJJ (1988). Pharmacologic aspects of cigarette smoking and nicotine addiction. New England Journal of Medicine, 319: 1318-1330.

51. Carney RM \& Goldberg AP (1984). Weight gain after cessation of cigarette smoking: a possible role for adipose-tissue lipoprotein lipase. New England Journal of Medicine, 310: 614-616. 